\title{
Morphological Characterization of Bacteria Using the Atmospheric Scanning Electron Microscope (ASEM)
}

K. Teramoto*, H. Nishiyama*, Y. Maruyama ${ }^{* *}$, Y. Konyuuba ${ }^{* * *}$, Y. Abe ${ }^{* * * *}$, D. Guarrera ${ }^{* * * *}$, M. Suga ${ }^{*}$, C. Sato ${ }^{* *}$

*JEOL Ltd., 1-2 Musashino 3-chome, Akishima, Tokyo 196-8558, Japan

** National Institute of Advanced Industrial Science and Technology, Tsukuba, 305-8566, Japan

*** JEOL Engineering Ltd., 1-2 Musashino 3-chome, Akishima, Tokyo 196-8558, Japan

**** Yamagata Research Institute of Technology, Matsuei 2-2-1, Yamagata, 990-2473, Japan

***** JEOL USA Inc., 11 Dearborn Road, Peabody, MA 01960

The classification of bacteria is important in many fields. Optical microscope (OM) observation of bacteria with Gram staining is valuable, but is limited in resolution due to the wavelength of light. DNA sequencing of $16 \mathrm{~S}$ ribosomal RNA has become useful for the identification of bacteria at the species level, thanks to improvements in DNA amplification techniques and DNA databases. This method, however, is not appropriate for the rapid identification of bacteria, since it requires time-consuming pretreatment.

To overcome these difficulties, we have developed a new Atmospheric Scanning Electron Microscope, (the ClairScope JASM-6200) [1 - 3] (Fig. 1). This instrument was designed with an inverted SEM column integrated with a wide field optical microscope. SEM imaging is through a thin silicon nitride ( $\mathrm{SiN}$ ) window incorporated in the ASEM sample holder (ASEM dish). The ASEM dish alone can be filled with a few $\mathrm{ml}$ of medium and used for prolonged cultivation of bacteria in an incubator. After fixation, the dish is placed on the ASEM stage. Although the thickness of the SiN film window is only $100 \mathrm{~nm}$, the ASEM dish endures a 1-atmosphere pressure differential and is transparent to electrons. The electron beam is projected upward through the film to the bacteria, and the electrons backscattered through the film are captured by a detector positioned below, for SEM imaging. The multi-step preprocessing necessary for conventional electron microscopy, including dehydration, is not required. Above the dish, an OM with an immersion lens can realize quasi-simultaneous observation.

In this study, we have investigated sample preparation methods for Gram-positive bacteria (Fig. 2 (a), (b)) and Gram-negative bacteria (Fig. 2 (c)). Bacterial cells were clearly observed after simple pretreatment with commonly-used fixing and staining reagents such as platinum-blue. This work suggests possibilities for the rapid identification of bacteria using the ASEM.

\section{References}

[1] H. Nishiyama et al., J. Struct. Biolog., in press.

[2] M. Suga et al., Microscopy and Microanalysis (2009), vol. 15, issue S2, p. 924.

[3] H. Nishiyama et al., Microscopy and Microanalysis (2009), vol. 15, issue S2, p. 938. 


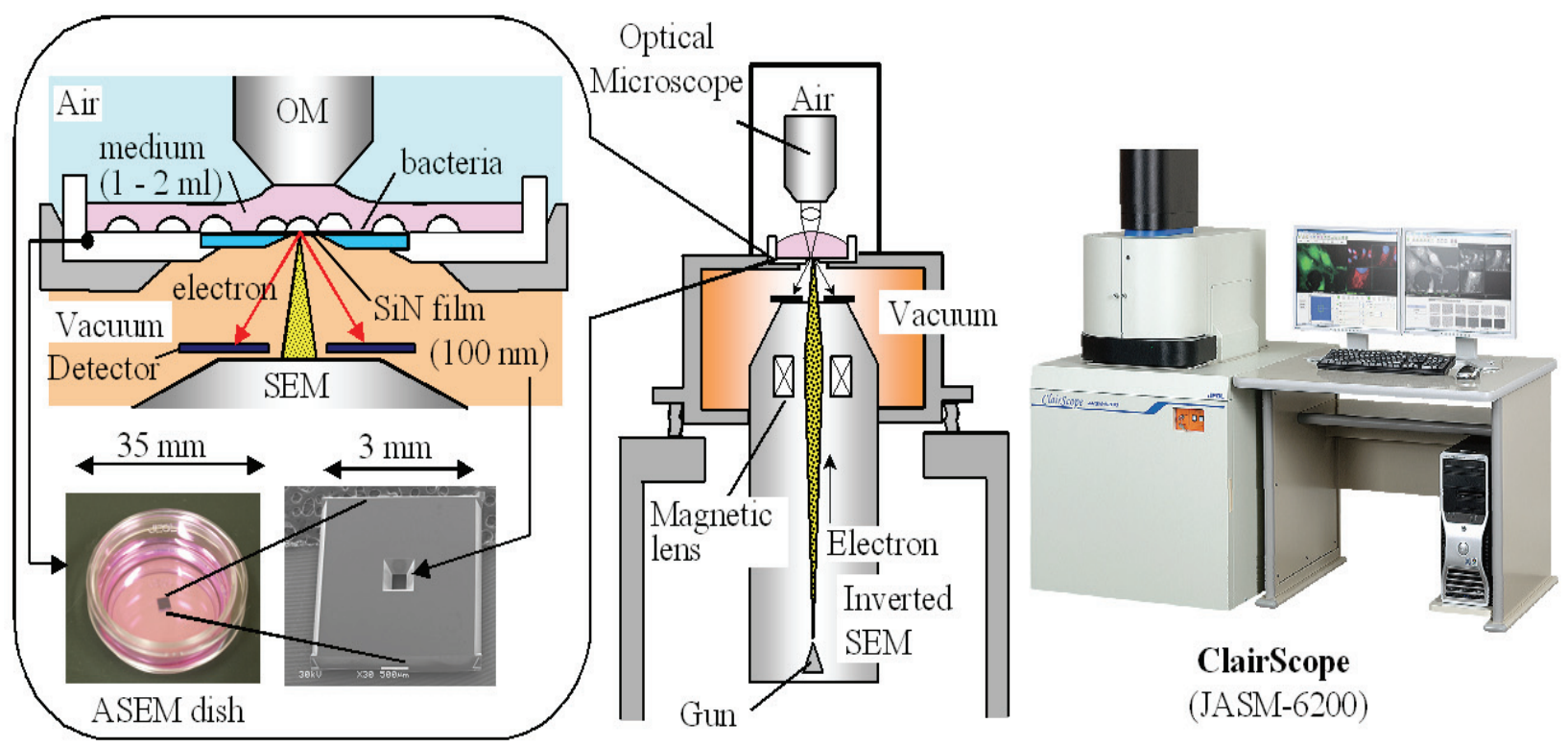

Fig. 1. Configuration of the ASEM. An optical microscope is arranged opposite an inverted SEM with the specimen dish between. The optical microscope is used to identify cell organelles in solution, using fluorescence. The culture dish features a SiN film window in its bottom plate. The film, while thin enough to transmit the electron beam, maintains the vacuum beneath. Electrons backscattered from the bacteria are detected for the acquisition of high-resolution SEM images.
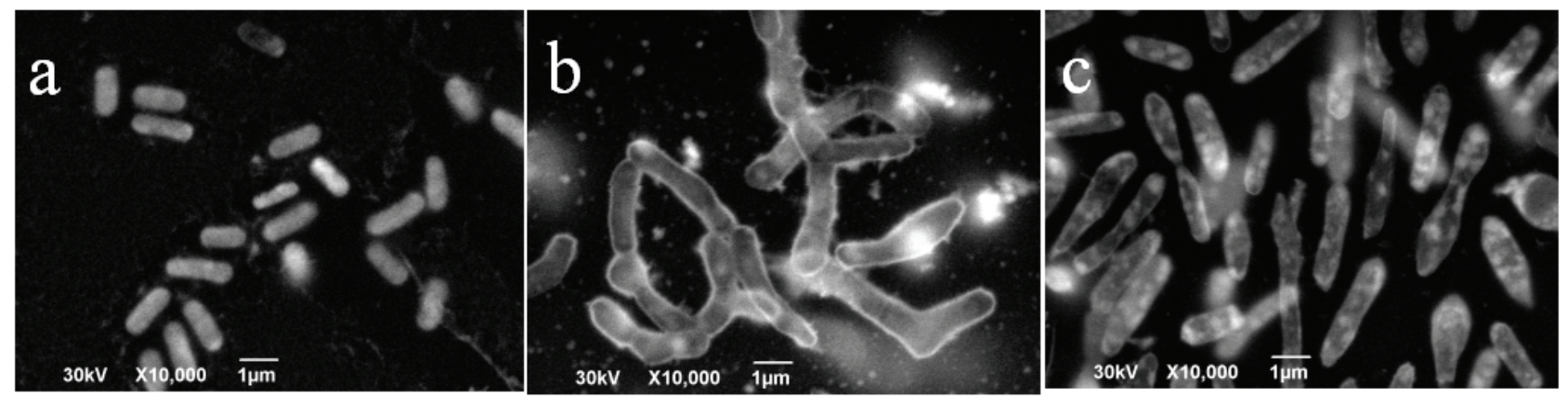

Fig. 2. ASEM images of Lactobacillus fermentum (a), Rhodococcus ruber (b), and Rhodobacter sphaeroides (c). 